\title{
CONSIDERAÇÕES SOBRE A ANÁLISE DO PROCESSO MIGRATÓRIO A PARTIR DA COMPLEXIDADE EM EDGAR MORIN
}

\author{
Florisbal de Souza Del'Olmo' \\ Diego Guilherme Rotta ${ }^{2}$
}

\section{RESUMO:}

O texto reflete a necessidade de análise do processo migratório a partir do paradigma da complexidade de Edgar Morin. Elabora-se a partir de revisão bibliográfica e documental. Parte-se do entendimento de que o processo migratório é um fenômeno complexo/em constante complexificação e a sua análise a partir da racionalidade instrumental não constitui uma dinâmica efetiva de produção de conhecimento, ações ou soluções para a "crise humanitária" enfrentada. Propõe-se a adoção de um modo de pensar e agir complexos, apto a compreender a trama de eventos que se inter-relacionam com o processo migratório e, consequentemente, propor soluções complexas ao fenômeno.

Palavras-chave: Processo migratório. Pensar. Construção do conhecimento. Racionalidade Instrumental. Complexidade.

\section{CONSIDERATIONS ON THE ANALYSIS OF THE MIGRATION PROCESS FROM THE COMPLEXITY IN EDGAR MORIN}

\begin{abstract}
The text reflects the need to analyze the migration process from Edgar Morin's paradigm of complexity. Undertake the same from bibliographic and documentary review. It is based on the understanding that the migration process is a complex / constantly complex phenomenon and its analysis based on instrumental rationality does not constitute an effective dynamics of knowledge production, actions or solutions to the "humanitarian crisis" faced. It is proposed to adopt a complex way of thinking and acting, able to understand the interplay of events that are interrelated with the migratory process and, consequently, to propose complex solutions to the phenomenon.
\end{abstract}

Keywords: Migratory process. Thinking. Knowledge construction. Instrumental rationality. Complexity.

\footnotetext{
${ }^{1}$ Pós-Doutor em Direito (UFSC). Doutor (UFRGS) e Mestre em Direito (UFSC). Especialista em Direito e em Educação. Graduação em Odontologia e Direito. Professor do Programa de Pós-Graduação Stricto SensuMestrado e Doutorado em Direito da URI, Santo Ângelo, RS. Líder do Grupo de Pesquisa registrado no $C N P q$ Tutela dos Direitos e sua Efetividade. Coordenador do Projeto de Pesquisa Direito Internacional do Trabalho e o resgate da dignidade e da cidadania. E-mail: florisbaldelolmo@gmail.com.

2 Mestrando bolsista no Programa de Pós-Graduação Stricto Sensu em Direito da Universidade Regional Integrada do Alto Uruguai e das Missões (URI), campus Santo Ângelo. E-mail: dg_rotta@ hotmail.com.
} 


\section{INTRODUÇÃO}

A movimentação de pessoas na superfície do globo terrestre é um fenômeno intrínseco na historicidade e desenvolvimento da civilização humana. Diferentemente das migrações protagonizadas por outros seres vivos, o processo migratório humano compreende uma gama de fatores que se inter-relacionam, não podendo ser analisado cientificamente a partir de uma mera relação de causa/efeito.

Diante de um cenário internacional cada vez mais globalizado, marcado por uma constância de conflitos armados, políticos, crises econômicas, desastres naturais, operações de terrorismo entre tantas outras causas que pulverizam uma amarga sensação de insegurança na atmosfera, muitas pessoas têm o deslocamento como única possibilidade de mudança/melhora de vida (ou, às vezes, única forma de manutenção da própria vida). Esse contexto catapultou o processo migratório ao status de fenômeno de proporções consideravelmente acentuadas, gerando o redirecionamento e a constante complexificação dos fluxos migratórios.

Em um movimento contrário à busca de novas alternativas ou formas de pensar/entender as múltiplas faces e manejar o processo migratório, a partir de uma lógica cartesiana de causa/efeito, coloca-se o "estrangeiro", o migrante, como totem das desgraças da modernidade, personificação das forças incontroláveis da modernidade, da insegurança, do medo e do terror.

Cristaliza-se, assim, uma nova dinâmica global de (re)fechamento das fronteiras, e a adoção de medidas/políticas de exclusão do "estrangeiro" acaba sendo empregada como uma espécie de "receita mágica simplificada", trazida pelos movimentos saudosistas nacionalistas/comunitaristas emergentes (encontrados nas novas lideranças políticas e “intelectuais" mundiais), fortalecendo plataformas eleitorais e a manutenção de um paradigma biopolítico ante as pessoas migrantes.

Contudo, sabe-se que a "crise humanitária" envolvendo o deslocamento de pessoas pelo globo terrestre não é um fenômeno novo, tendo já sido observada posteriormente às duas grandes guerras mundiais, e a construção de novas teorizações e soluções para o acolhimento e integração dessas pessoas (a título provisório ou permanente), adequadas à complexidade do processo migratório, é "pauta de ordem do dia”, devendo ultrapassar o modelo de políticas migratórias vigente. 
Partindo, pois, dessa intenção, dividir-se-á o presente artigo em dois pontos principais. No primeiro, destacar-se-á a adoção de modelos de pensamento e atuação fundados na exclusão do "estrangeiro", do "outro", como sintomas da condição humana e da modernidade. Pretende-se, sobretudo, apontar a (re)produção do paradigma biopolítico, a partir da securitização dos estados, como uma das "soluções fáceis" encontradas e empregadas na análise e tentativa de solução da complexidade (e constante complexificação) dos processos migratórios hodiernos.

No momento subsequente, apresentar-se-ão alguns aspectos principais do paradigma da complexidade a partir de Edgar Morin, advogando-se o emprego de tal método como uma possível solução para o rompimento e afastamento do modelo de análise dos movimentos migratórios hodiernos que fundamenta práticas de exclusão dos "estrangeiros" como soluções para a insegurança da modernidade.

\section{I - COMPLEXIFICAÇÃO DOS PROCESSOS MIGRATÓRIOS E CRISE HUMANITÁRIA: NECESSIDADE DE ENFRENTAMENTO DO PARADIGMA BIOPOLÍTICO DE (RE)FECHAMENTO DE FRONTEIRAS COMO "EASY WAY OUT"}

A mobilidade/movimento consiste em aspecto fundamental na relação dos seres vivos (animais, plantas) com o espaço em que habitam ou se desenvolvem. Pode ser entendida como um fenômeno biológico (DINGLE, DRAKE, 2007, p. 113-121), inerente à conservação da vida.

A constituição da própria condição do ser humano perpassa a sua relação com a espacialidade/territorialidade (HEIDEGGER, 2005, p. 90-102 e p. 152-163) e o "desejo incontido de movimentar-se, de explorar o desconhecido" e "romper com as amarras" do local onde nasceu na busca de melhores condições de vida ou solução de seus problemas (CAVARZERE, 1995, p. 02 e 08).

É nesse contexto que define-se a migração como movimento/circulação de pessoas dentro do território de determinado estado, ou para fora dele, a partir do cruzamento de fronteiras (IOM, 2004, p. 41; CAVARZERE, 1995, p. 09). No entanto, na esteira de Stephen Castells e Mark J. Miller (2004, p. 33), tem-se por mais apropriada a descrição do fenômeno migratório como um "processo migratório", eis que dificilmente consiste numa simples ação individual de uma pessoa, estabelecendo-se como um processo a largo prazo, que acompanha 
toda a vida do migrante e das pessoas à sua volta. É uma experiência, uma ação coletiva originada na mudança social e que também afeta toda a sociedade, nos espaços de saída de pessoas e também nos locais que recepcionam os migrantes (idem).

Por se tratar de um conjunto de fenômenos não completamente isolados, mas com variação no tempo e espaço, “O conceito de 'processo migratório' sintetiza intricados sistemas de fatores e interações que conduzem à migração internacional e influenciam no seu curso" (CASTELLS e MILLER, 2004, p. 34, tradução nossa). Por essa observação terminológica já se pode, em primeira instância, concluir que o processo migratório é um fenômeno complexo por sua própria natureza.

Para Thelma Thais Cavarzere (1995, p. 08) a circulação do ser humano pelo mundo foi e é motivada por causas de ordem natural, principalmente com relação ao homem primitivo, ou situações de ordem econômica, social e política, de maior influência preponderante (Idem, p. 08) nos processos migratórios da atualidade e, quiçá, durante os últimos séculos.

Apesar de muitas situações de movimentos de pessoas, com breves explicações de suas causas serem relatadas em textos históricos, religiosos ou a partir da cultura oral de muitos povos, a sua teorização científica é bastante recente.

Ao fazer um resgate das teorias de estudo das migrações internacionais, Elisa Massae Sasaki e Gláucia de Oliveira Assis (2000, p. 03), em um primeiro momento, trazem as contribuições da análise de Anthony H. Richmond (1988) sobre os teóricos clássicos Malthus, Marx, Durkheim e Weber, afirmando que, na virada do século XIX para o século XX, a migração era uma "preocupação secundária", "analisada como consequência do desenvolvimento do capitalismo, que, por sua vez, dá-se através da industrialização, urbanização e mobilidade populacional”.

Em um segundo estágio, as autoras (2000, p. 3-15) relatam que, a partir do século $\mathrm{XX}$, os estudos das migrações passam a ser encarados com maior profundidade, como um problema, despertando interesse dos sociólogos americanos, "dada a crescente mobilidade populacional da Europa para os países do Novo Mundo, particularmente os Estados Unidos” e dos estudiosos da economia e do funcionamento do mercado de trabalho, afim ao entendimento das redes sociais de migrações, ante a necessidade de complexificar as análises dos processos migratórios e compreender o contexto transnacional das redes e fluxos de migração. 
Referido aprofundamento nos estudos do processo migratório acabou por entregar à contemporaneidade teorias com diferentes aproximações fundamentais: as teorias a partir da perspectiva econômica neoclássica, a aproximação histórico-estrutural e a teoria dos sistemas migratórios (HUGO apud CASTLES e MILLER, 2004, p. 34).

A perspectiva econômica neoclássica, com origem no final do século XIX (Ravenstein) a-histórica e individualista, analisa os movimentos migratórios a partir da lógica de fatores de atração - fatores de retração ("push-pull”), sendo o migrante tratado como um "capital humano", um ser que se coloca na situação de deslocamento a partir da visualização da necessidade de estar em um local com melhores oportunidades, com maior desenvolvimento e possibilidades de satisfação pessoal (CASTLES e MILLER, 2004, p. 3538).

A aproximação histórico-estrutural, uma perspectiva alternativa para a migração internacional apresentada a partir dos anos setenta (1970), com raízes intelectuais na economia política marxista e na teoria do sistema mundial, enfatiza a distribuição desigual do poder econômico e político na economia mundial e visualiza os movimentos migratórios como resultantes de uma exploração da mão de obra barata e reforço do domínio das grandes economias capitalistas (CASTLES e MILLER, 2004, p. 38).

Tanto a aproximação neoclássica quanto a histórico-estrutural, deveras fechadas em si mesmas, acabam apresentando visões simplistas do processo migratório, desqualificando ou ignorando uma série de fatores que influenciam e são influenciados a partir da mobilidade das pessoas humanas. Talvez a maior crítica a ser apontada entre os dois modelos teóricos não sejam as suas falhas ou furos, mas a pretensão em funcionarem como sistemas fechados de análise de um fenômeno, sem procurar a comunicação com outras linhas de conhecimento.

Já a teoria dos sistemas migratórios, mais alinhada à proposta discutida neste trabalho, procura estudar as relações de envio e recepção baseadas na colonização, influência política, intercâmbio, inversão e vínculos culturais existentes entre os estados participantes dos fluxos migratórios (CASTLES e MILLER, 2004, p. 39-42). É um aporte teórico que observa ou procura constatar a interação entre as macroestruturas (fatores institucionais em grande escala, incluindo a economia política do mercado mundial, as relações entre os estados e as leis, os sistemas de políticas migratórias tratados entre os estados) e as microestruturas (redes, práticas e crenças dos migrantes, nas quais a família e a comunidade possuem forte influência) componentes do movimento de pessoas (idem). 
Defende-se, neste trabalho, que o emprego de tais formas de teorização e/ou estudo/tentativa de compreensão simplista do processo migratório não se mostram aptos ao processamento da complexa gama de relações envolvendo os movimentos de migração hodiernos e, ainda, aliados a outros fatores, fundamentam a criação de estados de securitização que servem a interesses de promoção política e acabam colocando o migrante num limbo jurídico, preso a um paradigma biopolítico.

Apesar de não constituir fenômeno novo, conforme explicitado anteriormente, o processo migratório hodierno é parte integrante de um novo panorama nas relações internacionais (CUTTI et al, 2016, posição 43), é mais intenso e mais dramático, apresentando um espectro maior de diversidade étnica, de classe e gênero, com relações múltiplas entre as sociedades de destino e origem (ASSIS, 2007), sendo quase impossível definir as direções dos fluxos ante a sua natureza cambiante (FIRMEZA, 2007, p. 17-18).

A dificuldade no entendimento do fenômeno migratório no seu estágio atual ainda encontra barreiras e alimenta os problemas decorrentes da própria condição da psique humana na relação com a alteridade.

De acordo com Sigmund Freud (2011, posição 211-218), além dos fatores de sofrimento advindos da programação biológica do corpo humano ao declínio e à dissolução (morte) e das desgraças do mundo externo (forças destruidoras que não podem ser controladas), a relação com os outros seres humanos, com a alteridade, é uma das causas mais dolorosas de sofrimento, é um "acréscimo um tanto supérfluo" que não pode ser evitado.

Em uma atmosfera moderna de constante medo e insegurança, o outro, fonte de ameaça presente e silenciosa deve ser constantemente vigiado, deixado no limbo, a fim de que o próprio excludente não passe a excluído e tenha que encarar a "morte metafórica" (BAUMAN, 2008, p. 69 e 92)

A figura do outro é representada pelo "estrangeiro", pelo migrante, pelo não pertencente ao estado, "captura e mantido numa 'zona cinzenta"” encarnando a ambivalência da inclusão pela sua exclusão (BAUMAN, 2008, p. 164).

O migrante/ "estrangeiro" é o "bode na sala" e o seu processo mortificante de manutenção no paradoxo da exclusão/inclusão acaba guiando muitas teorizações sobre o processo migratório e, consequentemente, a construção das políticas migratórias, fomentando o estabelecimento e perpetuação de políticas de securitização dos estados, desviantes dos olhares das “desgraças” praticadas pelos/dos governantes. 
Tal armadilha traduz-se nas práticas biopolíticas de manutenção da soberania dos Estados, em que o migrante vive um completo estado de exceção, de anomia do direito (AGAMBEN, 2002 e 2004). Vivendo à sorte dos interesses perversos do soberano/estado, o migrante pertence estando fora, é a vida matável e insacrificável capturada na esfera do poder soberano (AGAMBEN, 2002 e 2004 e SCHMITT, apud AGAMBEN, 2002, p. 23 ).

Esse é o paradigma político que floresce e se perpetua no cenário pós-11 de setembro de 2001, pautando o desenvolvimento das políticas migratórias a partir das ideias do retorno aos "Estados-Nação fortaleza de segurança máxima" de simplificação e afastamento das diferenças, uma homogeneidade cultural e étnica, a fim de propiciar melhor controle sobre a população e o território marca "um retorno às comunidades fechadas sobre si mesmo" (TOURAINE, 2006); e crescente restabelecimento de "tendências neotribais e fundamentalistas" e parâmetros de "fechamento" de fronteiras ao "outro" (BAUMAN, 1999).

Como efeito direto, tem-se a desertificação dos direitos humanos (dinâmica reversa ao processo de internacionalização e internalização dos direitos humanos) em que toda e qualquer norma interna ou externa com conteúdo de proteção aos direitos humanos poderá ser desrespeitada, ou simplesmente ter a sua aplicação e/ou eficácia suspensas ante a necessidade de preservar a segurança nacional, a soberania do Estado-Nação (PEREIRA, 2014, p. 53-78).

Construções teóricas que restam impossibilitadas ou bloqueadas ao aflorar de novos horizontes e perspectivas de exploração da construção do conhecimento tornam-se obsoletas diante da dinâmica de transformação do processo migratório hodierno. Em tais situações, a análise perante o fenômeno migratório ou resta deveras ultrapassada ou apresenta corruptelas lógicas diante da simplicidade estrutural que não oferece aporte à complexidade que acabam impulsionadas pela "insegurança" da modernidade e dificuldade de relação da psique humana com a alteridade (como já refletido anteriormente).

Dentre tais corruptelas geradas pela falta de entendimento do processo migratório, observa-se uma série de movimentos por parte de superpotências e seus governantes, bem como alguns eventos com cunho ideológico, tem encontrado ou apontado uma saída fácil para a complexidade das migrações que também consiste numa saída oportunista aos políticos ou derivada de seus programas.

Eventos emblemáticos como o referendo do Brexit (British Exit), ocorrido em 26 de junho de 2016, a partir do qual o Reino Unido deliberou pela "desintegração regional” a fim de melhor controlar os fluxos migratórios em suas fronteiras (DEL'OLMO; ROTTA, 2016, p. 113), a eleição do polêmico empresário Donald Trump como presidente dos Estados Unidos 
da América, em 09 de novembro de 2016, trazendo em sua campanha políticas de exclusão, deportação e reforço das barreiras migratórias, e os eventos em Charlotsville, na Virgínia/Estados Unidos, com "protestos" contra "não nacionais" vindos de grupos nacionalistas da supremacia branca de extrema-direita, demonstram a popularidade de plataformas políticas de "barramento" à presença do migrante/ "estrangeiro" e o retorno às ideologias nacionalistas de exclusão das diferenças, dos não pertencentes ao núcleo duro da nação.

Para Bauman (2017, posição 151-173), os migrantes, os “estrangeiros", são uma versão atualizada dos "homens-sanduíche" da década de 1920, que anunciavam o fím do mundo, pois são portadores das “enigmáticas, inescrutáveis, assustadoras e corretamente abominadas forças globais", que seriam as responsáveis pelo "perturbador e humilhante sentido de incerteza existencial que devasta e destrói nossa confiança”. Por portarem as más novas, esses "mensageiros", produtos da globalização, acabam tornando-se objeto da ira e raiva das pessoas desconfortadas com tais forças incontroláveis, o que, de acordo com Bauman (2017), é um "hábito humano - muito humano".

Aos migrantes são jogadas as "camisas" ou "máscaras" de sujeitos que "roubam os empregos da população nacional dos estados" ou "concorrem de maneira desleal", que "pesam nas contas do Estado social”, sugando os recursos dos programas e das políticas públicas, enfim, serve-lhe o papel de "párias sociais" que não podem ter a oportunidade ou possibilidade de estar ali.

Como aponta Pereira (2014, p. 73), a "figura abstrata do "estrangeiro", que intenta reconstruir a sua vida fora do país onde nasceu, é o que "mais sofre na pele a luta contra o terror e o rótulo de ameaça à segurança nacional", sendo bem-vindo tão somente até o ponto em que gera ganhos econômicos ao país que o recepciona.

Tal oportunidade de jogar toda a construção de sua popularidade sobre o combate aos "mensageiros" das forças que não conseguimos controlar, personificações das inseguranças e, de lambuja, solucionar uma situação deveras complexa, são "enganosamente reconfortantes a curto prazo", eis que deslocam o desafio do campo de visão", mas "essas políticas suicidas armazenam explosivos para uma detonação futura"” (BAUMAN, 2017, posição 173).

\footnotetext{
${ }^{3}$ Para Bauman (idem) diante de tal cenário, "a única forma de escapar dos atuais desconfortos e sofrimentos futuros passa por rejeitar as traiçoeiras tentações da separação".
} 
Esse "medo líquido" sustenta o enfrentamento da complexidade do processo migratório e das ameaças externas a partir da construção de novas políticas de fechamento de fronteiras e legalização da exclusão, em uma "adiaforização", um esquecimento da preocupação moral com o tema dos imigrantes (BAUMAN, 2017, posição 194 e 332).

Para Bauman (2017, posição 2082), “Os governos não estão interessados em aliviar as ansiedades de seus cidadãos", mas sim em alimentar esse sentimento que "nasce da incerteza quanto ao futuro e ubíquo sentimento de insegurança", colocando os governantes/políticos como grandes heróis garantidores da segurança. Esse processo de "securitização" é um "truque de mágica", somente desvia a ansiedade dos problemas que os governos são incapazes de enfrentar ou não têm muito interesse em fazê-lo (idem).

A humanidade e o projeto de manutenção dos direitos humanos já estabelecidos "andam em ovos" diante de tal pintura da paisagem internacional, razão pela qual há que ser dada maior atenção às novas formas de entender o processo migratório em seu estado da arte.

Os processos migratórios humanos não atendem a uma relação fechada e simplificada de causa-efeito como muitos dos hábitos de movimentações de outros seres vivos, realizados a fim de suprir a busca de alimentos, reprodução ou melhores condições climáticas $^{4}$ (RICARD, 1969 e ORR, 1986, apud PINTO, 2002, p. 3).

Tamanho é o grau de abrangência e influência do processo migratório que ele afeta e é afetado por todas as dimensões da existência social, desenvolvendo uma dinâmica própria, razão pela qual a teorização/investigação sobre o mesmo é (deve ser), intrinsecamente, uma mecânica interdisciplinar, devendo iluminar-se a partir de uma gama de ciências (CASTELLS e MILLER, 2004, p. 34).

Na mesma esteira, Hein de Haas (2014, p. 12) ressalta que o entendimento completo do cenário migratório hodierno não pode ser alcançado a partir de uma única ferramenta disciplinar; em verdade, requer uma abordagem ampla, a partir de uma gama de fontes teóricas e da análise dos contextos social e espaço-temporal, devendo ser excluídas as construções fáceis apontadas como soluções para o fenômeno.

Isso posto, tem-se que o movimento de securitização dos estados e construção de políticas migratórios fechadas, num paradigma biopolítico, a partir da "demonização" do "estrangeiro", da pessoa em constante movimento (migrante) como causadora do medo, das

\footnotetext{
${ }^{4}$ No entendimento de Moses (2013, pos. 747, tradução nossa), em função de sua complexidade, "a história da migração argumenta contra o uso de analogias simplistas com o reino animal”.
} 
inseguranças, do terrorismo, e sua consequente exclusão, além de resultado da aliança do "Zeitgeist" de insegurança da modernidade e da dificuldade de convívio com a alteridade, deve-se a uma patologia advinda da própria metodologia de estudo empregada na análise do atual estágio do processo migratório. Experiências teóricas deveras simplistas, que colocam o migrante ora como simples "capital humano", empregado, desempregado ou "ladrão de empregos".

Há que se buscar um novo modelo, ou novos modelos, novas possibilidades mais propícias à observação e construção de entendimento(s) sobre o complexo/em constante complexificação processo migratório hodierno, que fujam à simplificação da lógica de causa/efeito que coloca os migrantes em situação de desgraça, de vivente relegado a uma não vida, não pertença/exclusão. É o que se pretende discutir no próximo título.

\section{II - A IMPORTÂNCIA METODOLÓGICA DA COMPLEXIDADE A PARTIR DE EDGAR MORIN NA ANÁLISE DOS NOVOS PROCESSOS MIGRATÓRIOS}

A produção do conhecimento científico realiza-se, necessariamente, mediante o emprego de uma metodologia. A metodologia é “o caminho do pensamento e a prática exercida na abordagem da realidade" (MINAYO, 2013, posição 135), e “inclui simultaneamente a teoria da abordagem (o método), os instrumentos de operacionalização do conhecimento (as técnicas) e a criatividade do pesquisador (sua experiência, sua capacidade pessoal e sua sensibilidade)" (idem, posição 135).

O método científico, sobre o qual será pontuada a análise e posterior crítica neste trabalho, é um "traço característico da ciência”, um "instrumento básico que ordena, inicialmente, o pensamento em sistemas e traça os procedimentos do cientista ao longo do caminho", até a chegada no objetivo estabelecido primordialmente (TRUJILLO FERRARI apud PRODANOV, 2013, p. 24).

Considerando que, como já mencionado no capítulo anterior, pretende-se analisar a forma de abordagem e produção do conhecimento científico criado sobre o processo migratório hodierno, focar-se-á a discussão no presente capítulo sobre o método que se entende por mais adequado a um fenômeno tão complexo/em constante complexificação. 
Contudo, antes de apontar o método tido por mais adequado, há que se demonstrar o porquê da crítica com relação ao paradigma atual de análise científica do processo migratório, qual seja, o racionalismo instrumental.

A partir dos ideais iluministas, a produção do conhecimento científico deixou o território da metafísica e mergulhou na racionalidade instrumental/técnica pura, identificando a razão com a produtividade, para, a partir do saber, dominar aquilo que não era entendido (SILVA, 1997, p. 1-5). Ou seja, "Há uma intencionalidade pragmática originária na consciência intelectual, que foi expressa exatamente na identificação entre conhecer e dominar" (idem). Não bastava à ciência desvelar as faces ocultas do mundo, mas poder reproduzi-las, ter o controle sobre elas.

Para o professor Franklin Leopoldo e Silva, "a ciência, ao desencantar a natureza, isto é, ao substituir a relação com as forças pela formalização metódica de índole matematizante, apaziguou a exterioridade, destituindo-a de vida (SILVA, 1997, p. 5). Ou seja, ao mergulhar profundamente no racionalismo instrumental, objetivo, desprendendo-se totalmente das arguições metafísicas e animistas, seguindo os ideais do Iluminismo, a ciência, paradoxalmente, tolheu a sua própria pulsão de vida.

Uma das maiores celeumas diante de tal processo é que "O prestígio histórico das ciências exatas e naturais impôs às ciências do homem o mesmo paradigma", coisificando o homem, convertendo a emancipação em submissão ao próprio método, à própria razão instrumental (ADORNO e HORKHEIMER, apud SILVA, 1997, p. 5).

De acordo com Edgar Morin (2003, p. 68), até a metade do século XX, grande parte das ciências reduzia o método de construção de conhecimento ao determinismo como conceito principal, amarrando a produção científica e aplicando a "lógica mecânica da máquina artificial aos problemas vivos, humanos e sociais".

É essa aplicação da "lógica mecânica da máquina artificial", determinista e ocultadora do novo, que Morin pretende enfraquecer a partir da proposição do pensamento complexo como método de construção de conhecimento. Para ele,

A inteligência parcelada, compartimentalizada, mecanicista, disjuntiva, reducionista, destrói a complexidade do mundo em fragmentos distintos, fraciona os problemas, separa o que está unido, unidimensionaliza o multidimensional. Trata-se de uma inteligência ao mesmo tempo míope, hipermétrope, daltônica, caolha; ela muito frequentemente acaba ficando cega. Ela aborta todas as possibilidades de compreensão e de reflexão, eliminando, também, todas as possibilidades de um juízo corretivo ou de uma visão a longo prazo. Dessa forma, quanto mais os problemas se tornam multidimensionais, mais existe incapacidade de se pensar sua 
multidimensionalidade; quanto mais progride a crise, mais progride a incapacidade de se pensar a crise; quanto mais os problemas se tornam planetários, mais eles se tornam esquecidos. Incapaz de visualizar o contexto e a complexidade planetária, a inteligência cega se torna inconsciente e irresponsável (MORIN, 2003, p. 71).

É esse estreitamento da visão das ciências, que provoca a sua cegueira, a sua inconsciência e irresponsabilidade, (re)produzindo crises e construindo o prognóstico de morte da própria construção do conhecimento. No ensinamento de Morin (2003, p. 75), o pensamento complexo, apesar de não abandonar os princípios de ordem, de separabilidade e de lógica, os integra, em uma "concepção mais rica", reconhecendo a possibilidade de transgressão do modelo clássico de pensamento, haja vista que tal método permite uma "ida e vinda incessante entre certezas e incertezas, entre o elementar e o global, entre o separável e o inseparável”.

Dessa forma, há possibilidade de injetar-se vida nova à busca e construção do conhecimento a partir do pensamento complexo, haja vista que a partir da transgressão ele acaba com a força (re)produtora de crises e mortificante presente no pensamento racional instrumental. A fim de melhor expor o método de pensar a complexidade, Morin (2003, p. 7275) apresenta seus "sete princípios-guia", complementares e interdependentes, expostos a seguir.

O primeiro princípio, "princípio sistêmico, ou organizacional”, em clara oposição ao reducionismo, une o conhecimento das partes com o conhecimento do todo, não limitando a análise simplesmente a partir de uma perspectiva de soma das partes. O todo é mais do que a soma das partes e igualmente menos que a soma das partes. O princípio "hologramático", por sua vez, coloca em evidência "esse aparente paradoxo dos sistemas complexos nos quais a parte não somente está no todo, como o todo está inscrito na parte" (MORIN, 2003, p. 72). Cada célula que produz o holograma é parte de um todo e, ao mesmo tempo, carrega a totalidade das informações do objeto que representa ou pretende representar/mimetizar.

O terceiro princípio, chamado de "princípio do ciclo retroativo", apresentado por Norbert Wiener, traz luzes aos processos autorreguladores. Rompe-se com a linearidade, haja vista que a partir de tal princípio, tem-se que a causa age sobre o efeito, e o efeito sobre a causa, provocando a regulação e estabilização do sistema a partir dele mesmo.

Ao seu tempo, o "princípio do ciclo recorrente" "supera a noção de regulação pela de autoprodução e pela de auto-organização" (MORIN, 2003, p. 73). A partir de tal dinâmica, "os produtos e as consequências são, eles próprios, produtores e originadores daquilo que produzem" (idem). Nesse ponto, Morin apresenta o exemplo da humanidade como um 
processo que obedece a essa dinâmica, haja vista que "Os indivíduos humanos produzem a humanidade de dentro e por meio de suas interações, mas a sociedade emergindo, produz a humanidade desses indivíduos, fornecendo-lhes a linguagem e a cultura" (MORIN, 2003, p. 73).

O "princípio de autoecoorganização (autonomia/dependência)" revela que "os seres vivos são seres auto-organizações, que se autoproduzem sem cessar e por isso gastam a energia para salvaguardar sua autonomia" (MORIN, 2003, p. 73). A autonomia do ser humano é, paradoxalmente, dependente da retirada de energia, da informação e da organização do ambiente habitado por ele, dinâmica na qual morte e vida são complementares. De acordo com o pensador, esse é um princípio estritamente aplicável à situação dos humanos (idem).

O sexto princípio, "princípio dialógico", determina que dois princípios ou duas noções, ao mesmo tempo em que se excluem um ao outro, são indissociáveis em uma mesma realidade, situação essa ilustrada na fórmula heraclitiana ("viver de morte, morrer de vida"). A partir dessa relação dialógica, ordem/desordem/organização encontram-se profundamente inter-relacionados, na medida em que se sustentam por via de inúmeras "inter-retroações".

Para Morin (2003, p. 74), é o princípio dialógico que permite o aceite racional da “associação de noções contraditórias para conceber um mesmo fenômeno complexo". Mesmo que existente a tendência de exclusão um do outro, ambos os conceitos são aceitos e entendidos como possíveis dentro desse paradigma de construção de conhecimento.

O sétimo e último princípio, "o princípio da reintrodução do conhecido em todo o conhecimento", indica que "da percepção à teoria científica, todo o conhecimento é uma reconstrução/tradução por um espírito/inteligência em uma cultura e em tempo determinados" (MORIN, 2003, p. 75). O que já era apresentado como conhecimento volta a integrar o conhecimento na sua própria renovação, tendo como elemento variante o espaço-tempo e a cultura em que foi produzido e passou a reintegrar a própria produção do conhecimento.

Condensando os seus "sete princípios-guia", Morin (2003, p. 77) afirma que o pensamento complexo contempla a incerteza e também "é capaz de conceber a organização", é capaz de "reunir, contextualizar, globalizar, mas ao mesmo tempo de reconhecer o singular, o individual, o concreto". O pensar complexo possibilita um intercâmbio, uma "comunicação mútua" entre as formas de construção de conhecimento, perpassando os problemas de organizacionais, da sociedade, da política, e também da própria essência humana, "postulando a compreensão entre os humanos" (idem). 
A partir da análise dos escritos de Morin, Nelson Fiedler Ferrara (2010, p. 3, tradução nossa) destaca que o método formulado a partir da complexidade permite o pensamento dos fenômenos e da interação de vários fatores, onde "níveis de organização e dinâmicas não lineares podem ser identificadas a partir dos retornos entre os níveis", onde "regulação e não equilíbrio", "contingência e determinismo", "criação e destruição", "ordem e desordem" são, simultaneamente entendidos como possíveis e observados.

Em tal formulação (FIEDLER-FERRARA, 2010, p. 3, tradução nossa), os princípios produzidos por Morin para o pensar complexo, elencados anteriormente, encontram-se presentes a partir da dinâmica de retornos entre os níveis. Transparente, assim, que o pensar complexo trabalha em uma constante (re)produção de conhecimento (idem).

Fiedler Ferrara aduz que o pensamento complexo

[...] não assume que "tudo é complexo", significando "o que não pode ser entendido". Não é um pensamento de imprecisão e incerteza, apesar de incluir imprecisão e incerteza. Seu objetivo é trabalhar como uma base para ajudar na construção de conceitos e metodologias - ferramentas de pensamento, reflexão e ação no mundo -, para articular conhecimentos especializados. O pensamento complexo não é uma "teoria finalizada", mas um instrumento conceitual que está sendo elaborado (FIEDLER-FERRARA, 2010, p. 3, tradução nossa).

Ou seja, a utilização do método complexo para a análise de determinado fenômeno não serve como desculpa para deixar de tentar a situação, mas serve como um convite à não limitação da construção do conhecimento em uma fórmula matemática pronta, fechada, entendendo o próprio método de análise como uma constante evolução e renovação. Os limites estão presentes, também, mas não impedem completamente a renovação dos saberes, haja vista o próprio caráter de constante renovação e revolução do método e do pensar.

Morin (2003, p. 76) destaca que o pensamento a partir da complexidade não é algo inédito, pelo menos não na história da humanidade, encontrando numerosos elementos e premissas na filosofia ocidental e oriental. Ainda, de acordo com o pensador (2003, p. 76), no século XIX, a literatura, presente no romance de Balzac, Dostoievski e Proust, já revelava a complexidade humana. A contemporaneidade, ao seu tempo, tem como expoentes pensadores da complexidade na matemática (Wiener, von Neumann, von Foerster), na termodinâmica (Prigogine), na biofísica (Atlan) e na filosofia (Castoriadis) (idem).

No entanto, observa-se que ainda hoje, apesar do admirável avanço nas ciências duras, fonte histórica do racionalismo instrumental, algumas ciências sociais ainda padecem das limitações do pensamento cartesiano, da submissão da pessoa à razão, à determinação, 
almejando um melhor controle sobre as situações da vida social. Como exemplo dessa prisão quase perpétua à racionalidade instrumental, as ciências sociais aplicadas, colocando-se, aqui, ênfase na crítica ao Direito, diante de uma urgência na formação quase que exclusiva de profissionais técnicos, para garantir a manutenção e controle dos seus sistemas, acabam (re)produzindo um conhecimento meramente aplicador de fórmulas pré-estabelecidas, determinadas, tal qual verdadeiras fórmulas matemáticas.

Tal paradigma acaba sustentando a criação e manutenção de arcabouços jurídicos onde as inovações são quase que impenetráveis, resguardando velhas ideações em nome da segurança jurídica e do controle social. É o que pode ser visualizado no campo das migrações, onde a grande maioria das legislações dos Estados-Nação sequer fez adequações às declarações, tratados e resoluções de direitos humanos. Do contrário, acabam marchando cada vez mais para o retrocesso dos fechamentos e exclusões dos migrantes como solução simplificada e "segura".

O constante e complexo processo migratório, mais precisamente na figura dos migrantes, é apontado apena como causador das inseguranças e do terror, mas não observado, também, como efeito da própria dinâmica de exclusão e de fechamento que paira no contexto da modernidade.

Como afirmado anteriormente, o fenômeno social da migração, deveras complexo e em complexificação, necessita do desenvolvimento de novas formas de pensar, novas bases teóricas adaptáveis aos contextos sociais hodiernos, a partir de uma abordagem ampla, tomando em consideração todas as contingências espaço-temporais e expulsando as tentações das opções de construções de modelos fáceis (expulsão e exclusão dos migrantes) de solução de problemas (DE HAAS, 2014).

Os diferentes fluxos migratórios humanos observados atualmente não obedecem a uma relação de causa/efeito tão simples quanto os fluxos migratórios de outros seres vivos, conforme aduzido anteriormente. Da mesma forma, a presença de pessoas em constante movimento não pode ser tida como elemento causador, a partir de uma formulação simples, cartesiana, de atos de terrorismo, de medo, criando a necessidade de "securitização" da sociedade, de fechamento em fortalezas do Estado-Nação. Essas formas de análise somente expõem ainda mais o determinismo, a limitação, o caráter de reificação da própria pessoa humana presente no pensamento racional instrumental.

A partir do exposto, advoga-se, no presente artigo, que o modelo de pensamento fundado na complexidade, de pensar a complexidade, pode convergir com a já arguida 
necessidade de extrapolação do paradigma causa/efeito, da submissão das ciências humanas e, consequentemente, dos homens a coisas a serem controladas pelo exercício racional. Portanto, o pensar e consequentemente o agir dentro da complexidade, possibilita uma mirada para novas formas de encarar a complexidade/complexificação do processo migratório hodierno.

\section{CONCLUSÃO}

O processo migratório hodierno apresenta uma estrutura altamente complexa e em constante complexificação, e necessita de novas alternativas teóricas que evitem a simplificação de seu tratamento nas práticas de recrudescimento das políticas migratórias de fechamento de fronteiras e securitização de estados (que afastam a aplicação dos direitos humanos estabelecidos), possibilitando ao migrante o exercício de sua necessidade de busca de novas oportunidades em outros espaços.

Transparente que, partindo de um pensamento racional instrumental, determinado, limitado em fórmulas matemáticas, a análise do processo migratório no contexto hodierno não permite a construção de conhecimento, de um pensar e agir complexos perante um fenômeno altamente complexo/em constante complexificação. É uma forma limitada que deve ser transgredida. Do contrário, soluções fáceis, formas de "tapar o Sol com a peneira" continuarão a ser empregadas para "solucionar" as situações derivadas desse fenômeno.

Há, portanto, que se caminhar para um pensar e agir complexos perante a crise humanitária vivida em função dos movimentos migratórios presenciados na atualidade, eis que somente esse paradigma de construção de conhecimento encontra-se apto a desenvolver novas e diferentes formas de análise e possíveis soluções que se preocupem com toda a trama de eventos que a envolvem nas contingências espaço-temporais, enxertando o pensar e a produção de conhecimento com pulsões de (re)produção de vida. 


\section{REFERÊNCIAS}

AGAMBEN, Giorgio. Estado de exceção. Trad. Iraci D. Poleti. São Paulo: Boitempo, 2004.

Homo sacer: o poder soberano e a vida nua. Trad. Henrique Burigo. Belo Horizonte: Editora UFMG, 2002.

AMARAL, Augusto Jobim do. Introdução. Desconstruindo o terrorismo. In: BORGES, Rosa Maria Zaia; AMARAL, Augusto Jobim do; PEREIRA, Gustavo Oliveira de Lima (Orgs.).

Direitos humanos e terrorismo. Porto Alegre: EDIPUCRS, 2014.

ASSIS, Gláucia de Oliveira. Mulheres migrantes no passado e no presente: gênero, redes sociais e migração internacional. Estudos Feministas, Florianópolis, 15(3): 336, setembrodezembro/2007, p. 745-772.

BAUMAN, Zygmunt. Globalização: as consequências humanas. Trad. Marcus Penchel. Rio de Janeiro: Jorge Zahar Ed., 1999.

Comunidade: a busca por segurança no mundo atual. Trad. Plínio Dentzien. Rio de Janeiro: Jorge Zahar Ed., 2003.

Medo líquido. Trad. Carlos Alberto Medeiros. Rio de Janeiro: Zahar, 2008.

Estranhos à nossa porta. Versão: ebook. Trad. Carlos Alberto Medeiros. Rio de Janeiro: Zahar, 2017.

BEDIN, Gilmar Antonio; BÜRON, Luciane Montagner. Os direitos humanos e a proteção internacional de grupos específicos. Direito em debate. Ijuí, vol. 1, n. 1, p. 151-167, out 1991.

BÓGUS, Lucia Maria Machado. Globalização e migração internacional: o que há que novo nesses processos? In: DOWBOR, Ladislau; IANNI, Octavio; RESENDE, Paulo-Edgar A. (Orgs.). Desafios da globalização. Petrópolis, RJ: Vozes, 1997. p. 165-186.

CASTLES, Stephen; MILLER, Mark J. La era de la migración Movimientos internacionales de población en el mundo moderno. Colección América Latina y el Nuevo Orden Mundial. México: Miguel Ángel Porrua, UAZ, Cámara de Diputados LIX Legislatura, Fundación Colosio, Secretaría de Gobernación, Instituto Nacional de Migración, ISBN 970701-541-1, 2004.

CAVARZERE, Thelma Thais. Direito internacional da pessoa humana: a circulação internacional de pessoas. Rio de Janeiro: Renovar, 1995.

CUTTI, Dirceu, et al. Migração, trabalho e cidadania (versão e-book). São Paulo: EDUC, 2016.

DE HAAS, Hein. Migration theory. Quo vadis? IMI Working Paper Series 2014, November 2014, paper n. ${ }^{\circ}$ 100. Disponível em: 〈https://www.imi.ox.ac.uk/publications/wp-100-14〉. Acesso em: 15 set. 2016. 
DEL'OLMO, Florisbal de Souza; ROTTA, Diego Guilherme. "BREXIT”: da integração regional à política de controle de mobilidade humana. In: Revista brasileira de direito internacional, v. 2, n. 2, 2016, p. 100-117. Disponível em:

$<$ http://indexlaw.org/index.php/direitointernacional/article/view/1651>. Acesso em: 15 fev. 2017.

DINGLE, Hugh; DRAKE, V. Alistair. What is migration? In: BioScience. Feb 2007, vol. 57, Issue 2, p. 113-121. Disponível em: <http://www.bioone.org/doi/pdf/10.1641/B570206>. Acesso em: 30 jul. 2017.

FIEDLER-FERRARA, N. Complex thinking: building a new paradigma. Trans. Clarissa Almeida, Anja Pratschke. V!RUS, São Carlos, n. 3.:Nomads.usp, 2010. Disponível em < http://www.nomads.usp.br/virus/virus03/PDF/review/1_en.pdf>: Acesso em: 15 mar. 2017.

FIRMEZA, George Torquato. Brasileiros no exterior. Brasília: FUNAG, 2007.

FREUD, Sigmund. O mal-estar na civilização. Versão $e$-book. São Paulo: Editora Schwarcz Ltda., 2011.

HEIDEGGER, Martin. Ser e tempo. Parte I e Parte II. Trad. Marcia Sá Cavalcante Schuback. 15. ed. Petrópolis (RJ): Editora Vozes, 2005.

INTERNATIONAL ORGANIZATION FOR MIGRATION (IOM). Glossary on migration. International migration law. Geneva: International Organization for Migration, 2004.

KOLTAR, Caterina. O "estrangeiro" no processo de globalização ou a insustentável estrangeiridade do outro. In: DOWBOR, Ladislau; IANNI, Octavio; RESENDE, Paulo-Edgar A. (Orgs.). Desafios da globalização. Petrópolis, RJ: Vozes, 1997. p. 70-73.

MAQUIAVEL, Nicolau. O príncipe. Comentado por Napoleão Bonaparte. Trad. Pietro Nassetti. São Paulo: Martin Claret, 2008.

MENDES, Candido (Org.). Representação e complexidade. Rio de Janeiro: Garamond, 2003.

MILESI, Rosita. Em defesa dos direitos dos migrantes. REMHU - Revista Interdisciplinar Mobilidade Humana, Brasília, ano XXII, n. 43, p. 275-280, jul./dez. 2014.

MINAYO, Maria Cecília de Souza (Org.). Pesquisa social: teoria, método e criatividade. Versão: ebook. Petrópolis: Vozes, 2013.

MORIN, Edgar. A necessidade de um pensamento complexo. In: MENDES, Candido (Org.). Representação e complexidade. Rio de Janeiro: Garamond, 2003, p. 68-78.

MOSES, Jonathon W. International Migration. Globalization's Last Frontier (versão ebook). New York: Zed Books Ltd, 2013. 
NASCIMENTO, Elimar Pinheiro do. Globalização e exclusão social: fenômenos de uma nova crise da modernidade. In: DOWBOR, Ladislau; IANNI, Octavio; RESENDE, Paulo-Edgar A. (Orgs.). Desafios da globalização. Petrópolis, RJ: Vozes, 1997. p. 74-94.

PEREIRA, Gustavo Oliveira de Lima. Bem-vindo ao deserto dos direitos humanos: o 11 de setembro e o choque de fundamentalismos. In: BORGES, Rosa Maria Zaia; AMARAL, Augusto Jobim do; PEREIRA, Gustavo Oliveira de Lima (Orgs.). Direitos humanos e terrorismo. Porto Alegre: EDIPUCRS, 2014.

PINTO, Cynthia de Oliveira. As grandes migrações continentais. Monografia (Licenciatura em Ciências Biológicas). Centro Universitário de Brasília. Brasília, 2002.

PRODANOV, Cleber Cristiano; FREITAS Ernani Cesar de. Metodologia do trabalho científico: métodos e técnicas da pesquisa e do trabalho acadêmico. 2. ed., Novo Hamburgo: Feevale, 2013.

ROTTA, Diego Guilherme. Implicações da internalização da cultura do medo sobre os processos migratórios. In:Anais grupos de trabalho, v. 2, 2016. $2^{\circ}$ Encontro Missioneiro de Estudos Interdisciplinares em Cultura. Disponível em: <http://omicult.org/emicult/anais/wpcontent/uploads/2016/11/IMPLICA\%C3\%87\%C3\%95ES-DA-

INTERNALIZA\%C3\%87\%C3\%830-DA-CULTURA-DO-MEDO-SOBRE-OSPROCESSOS-MIGRAT\%C3\%93RIOS-2.pdf>. Acesso em: 10 ago. 2017.

SASAKI, Elisa Massae; DE OLIVEIRA ASSIS, Gláucia. Teorias das migrações internacionais. In: Anais do XII Encontro Nacional de Estudos Populacionais, 2000, Sessão Temática 16, p. 1-19. Disponível em:

<http://www.abep.org.br/ abeporgb/publicacoes/index.php/anais/article/view/969/934>. Acesso em: 20 fev. 2017.

SEVERINO, Antônio Joaquim. Metodologia do trabalho científico. São Paulo: Cortez, 2007.

SILVA, Franklin Leopoldo e. Conhecimento e Razão Instrumental. Psicol. USP, São Paulo, v. 8, n. 1, p. 11-31, 1997. Disponível em:

$<$ http://www.scielo.br/scielo.php?script=sci_arttext\&pid=S010365641997000100002\&lng=en \&nrm=iso>. Acesso em: 27 mar. 2017.

SPOSATI, Aldaíza. Globalização: um novo e velho processo. In: DOWBOR, Ladislau; IANNI, Octavio; RESENDE, Paulo-Edgar A. (Orgs.). Desafios da globalização. Petrópolis, RJ: Vozes, 1997, p. 43-49.

TOURAINE, Alain. Um novo paradigma: para compreender o mundo de hoje. Trad. Gentil Avelino Titton. Petrópolis/RJ: Vozes, 2006.

UNESCO. Declaração universal dos direitos humanos. Disponível em:

<http://unesdoc.unesco.org/images/0013/001394/139423por.pdf>. Acesso em: 03 dez. 2017.

WELLAUSEN, Saly da Silva. Terrorismo e os atentados de 11 de setembro. Tempo social; Rev. Sociol. USP. São Paulo, 14(2): 83-112, outubro de 2002. 